\title{
COMMENTARY
}

\section{Immunotherapy - a potential new way forward in the treatment of sepsis}

\author{
Didier Payen ${ }^{* 1}$, Guillaume Monneret ${ }^{2,3}$ and Richard Hotchkiss ${ }^{4}$ \\ See related research by Wu et al., http://ccforum.com/content/17/1/R8
}

\begin{abstract}
A recent randomized controlled clinical trial of the immunostimulatory agent thymosin alpha-1 was conducted and showed a trend toward improved survival in patients receiving the drug $(P=0.06)$. Although this was a relatively small study and the exact mechanism of action of thymosin alpha- 1 is not known, the present results further support the evolving concept that, as sepsis persists, a hypoinflammatory and immunosuppressive condition ensues and therapy that augments host immunity may be advantageous. Other immunomodulatory agents including granulocyte-macrophage colony-stimulating factor have shown promise in small trials in sepsis. In addition, there are a number of new immunoadjuvant agents such as IL-7 and anti-programmed cell death-1 that are showing remarkable abilities to enhance host immunity and improve outcomes in a variety of clinical disorders, including cancer and chronic viral infections. Animal studies show that these new immunoadjuvant agents improve survival in several clinically relevant models of sepsis. Given the relative safety of thymosin alpha-1 and these other new immunomodulatory agents as well as the persisting high mortality of sepsis, a strong case can be made for larger well-designed trials using immunoadjuvant therapy in patients who have documented immune suppression. Immunotherapy offers new hope in the treatment of sepsis and may dramatically change the face of the disease.
\end{abstract}

The article from $\mathrm{Wu}$ and colleagues investigates the question of using immunostimulation as a new approach in treating sepsis [1]. The incidence of sepsis, and particularly severe sepsis, is expected to markedly increase in

*Correspondence: dpayen1234@orange.fr

'AP-HP Département d'Anesthésie-Réanimation, Hôpital Lariboisière, Université

Paris 7 Diderot, EA 3509, 2 rue Ambroise Paré, 75010 Paris, France

Full list of author information is available at the end of the article the next decade due to the aging population and more widespread use of therapies that compromise host immunity in cancer and autoimmune diseases. A better strategy to reduce mortality in severe sepsis thus remains an absolute necessity.

Advances in sepsis therapy have occurred and the Surviving Sepsis Campaign recommendations have led to a reduction in sepsis mortality from roughly $50 \%$ to $\sim 30$ to $35 \%$ [2]. The remaining high rate of death and the failure of the most recent high-profile clinical trials in sepsis still argue for an innovative adjuvant approach to this highly lethal disease [3]. Beyond the design of these trials, incertitude on some key pathophysiologic mechanisms should be clarified to allow change in the paradigms of sepsis syndrome and patient care. Among the newly accepted concepts, the occurrence of immunodepression soon after the initial phase of sepsis has gained credibility. To be clinically relevant, such a concept has: to be confirmed in a large-size population; to be diagnosed and quantified by standardized methods; to be observed not only on circulating immune cells, but also within organs that fail in sepsis; to be based on molecular mechanisms; and to be reversible, even partially, by clinical-based therapy able to improve outcome. Almost all of these criteria have been validated in clinical conditions, except the proven benefit for outcome. The article from $\mathrm{Wu}$ and colleagues addressed this question using thymosin alpha-1 (T $\alpha 1)$ [1], a molecule with known immunostimulating properties [4].

The concept of sepsis-induced immunodepression has been extensively described ex vivo, especially in septic monocytes, with impaired responses to additional immune challenges compared with healthy cells. Importantly [5], such immunodepression was recently demonstrated to occur in immune cells infiltrating into organs in patients dying from severe sepsis [6]. Remarkable to note is that most immune effector cells are involved, resulting in defects in both innate and adaptive immunity [7]. Moreover, the magnitude and duration of immunosuppression are now well documented to be associated with worse outcome and increased risk for nosocomial infections [8]. The underlying mechanisms are complex: 
the predominance of anti-inflammatory cytokines [9]; the alteration of T-lymphocyte populations in number and function [6]; the fractional increase in T-regulatory inhibitory lymphocytes [10]; metabolic failure of immune cells [11]; and epigenetic modifications induced by the cell microenvironment [12].

Interestingly, this immunodepression has been shown to be reversible using different immunostimulatory therapies including IFNY [13], granulocyte-macrophage colony-stimulating factor [14], and, recently, IL-7 [15]. Such treatments may boost host immunity, thereby leading to more effective eradication of the primary infection, prevention of secondary infection, decreasing latent virus reactivation and, hopefully, improving outcome.

The present randomized control trial of T $\alpha 1$ is in line with this new direction. Despite a lack of understanding of some of its mechanism(s) of action, immunomodulatory activity of $T \alpha 1$ on effector cells of the innate

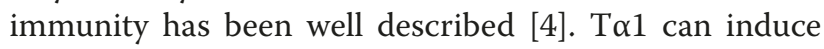
T-cell and dendritic cell maturation as well as increasing IL-12 expression.

This randomized controlled trial tested the early administration of $\mathrm{T} \alpha 1$ on day- 7 and day- 28 mortality and on severity of organ failure and mHLA-DR expression. The main result was a reduction in 28-day mortality in the Ta1 group (26\%) versus the control group (36\%) $(P<0.06)$ with an associated increase in mHLA-DR and no change in severity of organ failure.

The moderate outcome benefit may result from several limitations well mentioned by the authors. Perhaps more importantly, two issues may limit the observed benefit. First, the trial is designed to reduce crude mortality, which includes both sepsis-attributable mortality and mortality related to underlying disease. An adjunctive immune therapy would only impact septic-induced organ failure and death and would require a larger study population. Second, the drug or the placebo was given to all patients having the entry criteria that were not based on immune competence. The results might have been different if enrollment of the patients had been based on immune monitoring and restricted to those patients with documented immunosuppression.

Despite its significant limitations and undefined mechanism of action, this randomized control trial is one of the first such trials using a known immunostimulating agent to reduce 28-day mortality. Despite the largely unknown mechanism of action of the drug and nonselection based on assessed immunodepression, the observed marginal positive $P$ value in favor of T $\alpha 1$ confirms the interest to perform other carefully conducted immunotherapeutic trials based upon markers of immune suppression.

\section{Competing interests}

DP has received grant support from Meditor. $\mathrm{RH}$ has received grant support from Britol Meyers Squibb and Medimmune. GM has no competing interests.

\section{Abbreviations}

IFN, interferon; IL, interleukin; Ta1, thymosin alpha-1.

\section{Author details}

${ }^{1}$ AP-HP Département d'Anesthésie-Réanimation, Hôpital Lariboisière, Université Paris 7 Diderot, EA 3509, 2 rue Ambroise Paré, 75010 Paris, France. 'Laboratoire d'Immunologie - Hôp. E, Herriot, Hospices Civils de Lyon, 69003 Lyon, France. ${ }^{3}$ Université Lyon I, Hospices Civils de Lyon, EAM 4174, 69008 Lyon, France. ${ }^{\circ}$ Department of Anesthesiology, Medicine, and Surgery, Washington University School of Medicine, 660 S. Euclid, St Louis, MO 63110, USA.

\section{Published: 20 February 2013}

\section{References}

1. Wu J, Zhou L, Liu J, Ma G, Kou Q, He Z, Chen J, Ou-Yang B, Chen M, Li Y, Wu X, Gu B, Chen L, Zou Z, Qiang X, Chen Y, Lin A, Zhang G, Guan X: The efficacy of thymosin alpha 1 for severe sepsis (ETASS): a multicenter, single-blind, randomized and controlled trial. Crit Care 2013, 17:R8.

2. Levy MM, Dellinger RP, Townsend SR, Linde-Zwirble WT, Marshall JC, Bion J, Schorr C, Artigas A, Ramsay G, Beale R, Parker MM, Gerlach H, Reinhart K, Silva E, Harvey M, Regan S, Angus DC; Surviving Sepsis Campaign: The Surviving Sepsis Campaign: results of an international guideline-based performance improvement program targeting severe sepsis. Crit Care Med 2010, 38:367-374.

3. Cohen J, Opal S, Calandra T: Sepsis studies need new direction. Lancet Infect Dis 2012, 12:503-505.

4. Serafino A, Pierimarchi P, Pica F, Andreola F, Gaziano R, Moroni N, Zonfrillo M, Sinibaldi-Vallebona P, Garaci E: Thymosin alpha1 as a stimulatory agent of innate cell-mediated immune response. Ann N Y Acad Sci 2012, 1270:13-20.

5. Munoz C, Carlet J, Fitting C, Misset B, Blériot J, Cavaillon J-M: Dysregulation of in vitro cytokine production by monocytes during sepsis. J Clin Invest 1991, 88:1747-1754.

6. Boomer JS, To K, Chang KC, Takasu O, Osborne DF, Walton AH, Bricker TL, Jarman SD, 2nd, Kreisel D, Krupnick AS, Srivastava A, Swanson PE, Green JM, Hotchkiss RS: Immunosuppression in patients who die of sepsis and multiple organ failure. JAMA 2011, 306:2594-2605.

7. Monneret G, Venet F: A rapidly progressing lymphocyte exhaustion after severe sepsis. Crit Care 2012, 16:140.

8. Lukaszewicz AC, Grienay M, Resche-Rigon M, Pirracchio R, Faivre V, Boval B, Payen D: Monocytic HLA-DR expression in intensive care patients: interest for prognosis and secondary infection prediction. Crit Care Med 2009, 37:2746-2752.

9. Fumeaux T, Pugin J: Role of interleukin-10 in the intracellular sequestration of human leukocyte antigen-DR in monocytes during septic shock. Am J Respir Crit Care Med 2002, 166:1475-1482.

10. Venet F, Chung CS, Kherouf H, Geeraert A, Malcus C, Poitevin F, Bohe J, Lepape A, Ayala A, Monneret G: Increased circulating regulatory T cells (CD4(+)CD25(+)CD127(-)) contribute to lymphocyte anergy in septic shock patients. Intensive Care Med 2009, 35:678-686.

11. Belikova I, Lukaszewicz AC, Faivre V, Damoisel C, Singer M, Payen D: Oxygen consumption of human peripheral blood mononuclear cells in severe human sepsis. Crit Care Med 2007, 35:2702-2708.

12. Carson WF, Cavassani KA, Dou Y, Kunkel SL: Epigenetic regulation of immune cell functions during post-septic immunosuppression. Epigenetics 2011, 6:273-283.

13. Docke WD, Randow F, Syrbe U, Krausch D, Asadullah K, Reinke P, Volk HD, Kox W: Monocyte deactivation in septic patients: restoration by IFN-gamma treatment. Nat Med 1997, 3:678-681.

14. Meisel C, Schefold JC, Pschowski R, Baumann T, Hetzger K, Gregor J, Weber-Carstens S, Hasper D, Keh D, Zuckermann H, Reinke P, Volk HD: Granulocyte-macrophage colony-stimulating factor to reverse sepsisassociated immunosuppression: a double-blind, randomized, placebocontrolled multicenter trial. Am J Respir Crit Care Med 2009, 180:640-648.

15. Venet F, Foray AP, Villars-Mechin A, Malcus C, Poitevin-Later F, Lepape A, Monneret G: IL-7 restores lymphocyte functions in septic patients. $\mathrm{J}$ Immunol 2012, 189:5073-5081.

doi: $10.1186 /$ cc12490

Cite this article as: Payen $D_{\text {, et }}$ al: Immunotherapy - a potential new way forward in the treatment of sepsis. Critical Care 2013, 17:118. 